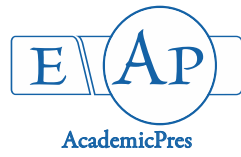

\title{
Microbiological Characterization of Grilled Meat "Tchatchanga” in Cotonou (Southern Benin): Enumeration, Isolation and Resistance Profile of Staphylococcus aureus and Escherichia coli
}

\author{
Ousmane ASSIM ${ }^{1}$, Victorien T. DOUGNON ${ }^{2 *}$, Nicodème W. CHABI ${ }^{1}$, \\ Jerrold A. AGBANKPE ${ }^{2}$, Alidah V. ANIAMBOSSOU², \\ Kafayath A. FABIYI ${ }^{2}$, Lamine BABA-MOUSSA ${ }^{3}$ \\ ${ }^{1}$ University of Abomey-Calavi, Laboratory of Teaching and Research in Microbiology, Department of Food Technology Engineering, Polytechnic \\ School of Abomey-Calavi, 01 BP 2009 Cotonou,Benin; nicodeme.chabi@gmail.com \\ ${ }^{2}$ University of Abomey-Calavi, Research Unit in Applied Microbiology and Pharmacology of Natural Substances, Laboratory of Research in \\ Applied Biology, Polytechnic School of Abomey-Calavi, 01 BP 2009 Cotonou,Benin; urmaphaepac@hotmail.com, \\ victorien88@hotmail.com (*corresponding author) \\ ${ }^{3}$ University of Abomey-Calavi, Laboratory of Biology and Molecular Typing in Microbiology, Faculty of Science and Technology, 05 BP 1604 \\ Cotonou,Benin; laminesaid@yahoo.fr
}

\begin{abstract}
Collective food-borne diseases are the reason for a considerable number of deaths in developing countries. The contamination of meat is often noticed. The purpose of the present study was to enumerate, isolate and evaluate the resistance profile of Staphylococcus aureus and Escherichia coli in grilled meat consumed in Southern Benin. To achieve this goal, 30 thirty samples of grilled meat "Tchatchanga" were collected in three districts of the city of Cotonou. After collection, the samples were identified, stored in a cooler containing cold accumulator's and sent to the laboratory for analysis. The resistance profile of the different isolated strains was then sought: $30 \%$ of the samples were contaminated with Escherichia coli and $100 \%$ with Staphylococci. In terms of hygienic quality, $70 \%$ of the samples were of unsatisfactory. Of the 30 staphylococcal strains, 11 were identified as Staphylococcus aureus. Regarding the strain resistance profile, $88.89 \%$ of the Escherichia coli strains were multi-resistant compared to $72.72 \%$ of Staphylococcus aureus. This study revealed the necessity of urgent actions to ensure food safety in Benin.
\end{abstract}

Keywords: bacteria in food; food safety; grilled meat; resistance profile of bacteria in food; Tchatchanga

\section{Introduction}

Meat is considered a food of choice because of its nutritional value. Its richness in protein and the nature of these make it an essential food for a balanced diet. However, because of its nutritional qualities, meat constitutes a very favourable ground for most microbial contaminations (Djenidi, 2016).

Meat is the transformation product of muscle after the death of the animal. She is traditionally considered the vehicle many foodborne illnesses in humans because of poor hygiene (Fosse et al., 2006; Salifou et al., 2013). The microbiological risks and food-borne diseases they cause are a growing problem for public health (WHO, 2002).
Collective food-borne illness leads to a considerable number of deaths worldwide in developing countries (Bankolé et al., 2012).

In Europe, the mortality due to food poisoning is small, but a number of 50.000 acute gastroenteritis per million inhabitants per year is commonly advanced (Delmas et al., 2006). In Morocco, between 2000 and 2004, 7.118 cases of food poisoning were reported, more than $86 \%$ of which are of bacterial origin (Cohen et al., 2006). Contamination of food of animal origin and mainly meat and meat products is responsible for 28\% of TIAC cases (Khallaf et al., 2014). The conditions of treatment of the meat expose it to contamination of any kind including microbial (Ahouandjinou et al., 2016). In addition, there is a risk of 
40

development and growth of contaminating flora during cooling, storage and distribution (El-Hadef et al., 2005).

In developed countries, nearly $30 \%$ of the population has a food-borne illness and the proportion is undoubtedly higher in developing countries (WHO, 2011). Infectious diseases of food origin (or collective food poisoning) are often linked to health defects and can be very serious, predominantly involving the bacteria salmonella, enterotoxigenic Escherichia coli and coagulase-positive staphylococci (Benaissa et al., 2014; Yeni et al., 2014).

The growth of staphylococci in food is a risk to public health because some strains belonging mainly to the Staphylococcus aureus species produce enterotoxins whose ingestion causes food poisoning resulting in severe vomiting accompanied by diarrhea (Martins et al., 2014). The interest is mainly hygienic when it comes to $E$. coli species. This bacterium is considered a normal host of the digestive microflora of humans and many animal species. As such, $E$. coli and more widely thermos-tolerant coliforms are sought in food as indicators of faecal contamination; some strains of this bacterium can however be pathogenic for humans. Their presence indicates the possible contamination of the food by pathogenic bacteria of enteric origin, especially salmonella (Cohen et al., 2006).

In the current context of increasing food safety requirements, it is becoming urgent to acquire reliable data on the prevalence of these germs in the highly prized grilled meat in southern Benin. The objective of this study is to enumerate isolate and evaluate the resistance profile of Staphylococcus aureus and Escherichia coli in grilled meat consumed in southern Benin.

\section{Materials and Methods}

\section{Biologicalmaterial}

The biological material consisted essentially of 30 samples of grilled meat. In the present study, the samples of grilled meat obtained from a few broilers in Zongo, Mènontin and Gbegamey in Cotonou were used. The grilled meat samples were collected using a sterile fork and put into sterile sampling bags. After collection, the whole was identified and stored in cooler containing cold accumulators. Then everything is sent to the laboratory for analysis.

\section{Sampling equipment}

The collection of food was done using appropriate sampling equipment: sterile sampling bags, sterile spoons, sterile forks, a pair of sterile forceps and a cooler.

\section{Laboratory equipment}

Glassware was composed of beakers, Erlenmeyer flasks, sterile screw tubes, sterile Petri dishes and others.

Facilities used were the bacteriological ovens, refrigerator, autoclave, etc.

\section{Culture media}

Baird Parker with egg yolk enriched with potassium tellurite, TBX, MH, Heart-Brain broth was used as culture medium.
Other materials used were carded cotton, aspirated pear, graduated pipettes, alcohol, antibiotic discs, sterile peptone water, oxidase discs, Kovacs reagent, hydrogen peroxide, freeze-dried rabbit plasma, rack, sterile scissors, sterile forceps, and markers.

\section{Microbiological analyses \\ Preparation of the decimal dilutions}

The stock suspension is the dilution from which the successive dilutions were made. $45 \mathrm{ml}$ of peptone water was added to $5 \mathrm{~g}$ aseptically weighed of sample, all in a sterile stomacher bag. The whole was crushed. The stock suspension thus obtained corresponds to the $10^{-1}$ dilution. From this suspension, decimal dilutions were carried out.

As regards the preparation of serial tenfold dilutions, a volume of $1 \mathrm{~mL}$ of the stock suspension was taken and put into a tube containing $9 \mathrm{~mL}$ of sterile peptone water. The whole has been homogenized. The dilution thus obtained was at $10^{-2}$. A volume of $1 \mathrm{~mL}$ of the dilution $10^{-2}$ was taken and put in a tube containing $9 \mathrm{~mL}$ of sterile peptone water. The whole has been homogenized. The resulting dilution was $10^{-3}$ and so on.

\section{Enumeration and isolation of Escherichia coli}

The culture of $E$. coli was made by incorporation into TBX agar. $1 \mathrm{~mL}$ of each of the successive dilutions retained was introduced into different sterile petri dishes, and then about $20 \mathrm{~mL}$ of the medium TBX were cast there in. The whole was homogenized and allowed to solidify. After solidification, the dishes were incubated at $44{ }^{\circ} \mathrm{C}$ for $24 \mathrm{~h}$. On TBX blue colonies were obtained. These suspect colonies were enumerated; an isolated colony was seeded on nutrient agar and incubated at $37{ }^{\circ} \mathrm{C}$ for 24 hours for purification.

\section{Identification Escherichia coli}

The pure colonies obtained after $24 \mathrm{~h}$ incubation at $37{ }^{\circ} \mathrm{C}$ were used for biochemical identification tests, including Gram stain, catalase search, oxidase and inoculation of the API $20 \mathrm{E}$ gallery.

\section{Enumeration and isolation of Staphylococcus aureus}

The enumeration and isolation of the strains was carried out according to the method described by Speek (1976). 0.1 $\mathrm{mL}$ of the stock suspension and various decimal dilutions were transferred to the surface of Baird-Parker agar plates enriched with potassium tellurite and egg yolk. The inoculum was carefully spread on the agar medium and the dishes were then incubated at $37^{\circ} \mathrm{C}$ for $48 \mathrm{~h}$. The black, smooth, rounded, regular-contoured colonies with one or two characteristic halos were enumerated.

\section{Identification of strains of Staphylococcus aureus}

The identification of $S$. aureus strains was made by complementary tests, namely: Gram stain, catalase, coagulase and DNase.

\section{Strain resistance profile}

An antibiogram was performed for each bacterial sample isolated by diffusion method Mueller-Hinton agar medium in accordance with the recommendations of the 
Antibiogram Committee of the French Society of Microbiology (CASFM, 2012).

On the strains of Escherichia coli, the antibiotics tested were gentamycin $(500 \mu \mathrm{g})$, cefotaxime $(30 \mu \mathrm{g})$, ciprofloxacin $(5 \mu \mathrm{g})$ and nalixidic acid $(30 \mu \mathrm{g})$. For strains of Staphylococcus aureus, amoxicillin $(20 \mu \mathrm{g})$ + clavulanic acid $(10 \mu \mathrm{g})$, imipenem $(10 \mu \mathrm{g})$, cefotaxime $(30 \mu \mathrm{g})$ and gentamycin $(500 \mu \mathrm{g})$ were used.

The strains reference (Escherichia coli ATCC 25923 and Staphylococcus aureus ATCC 25922), as well as the strains to be tested were previously subcultured on the $\mathrm{MH}$ agar and incubated $24 \mathrm{~h}$ at $37^{\circ} \mathrm{C}$ in order to provide young stem. For each strain inoculum correspondent standard McFarland 0.5 has been prepared. Using a sterile swab, the inoculum obtained was seeded by swabbing on dried MH II medium. The spreading was rotated three times in order to obtain a homogeneous distribution of the inoculum. The pre-impregnated antibiotic discs were then gently deposited on the surface of the agar with sterilized forceps. The agar plates were incubated for $24 \mathrm{~h}$ at $37^{\circ} \mathrm{C}$ in an oven.
The diameters of the inhibition zones were finally measured using a vernier caliper applied in contact with the rear face of the box. Compared to antibiotic inhibition reference diameters, the resistance profile of the probes was determined (CASFM, 2016).

\section{Results}

Enumeration of Staphylococci and E. coli

Organic acids and sugars and their ratios, together with different aromatic compounds, play important roles in the character and quality of the flavour and organoleptic properties of apples. Malic and citric acid were detected in apple fruit cultivars. The fruits of different cultivars contained higher amounts of malic acid than citric acid (Table 1). At the end of the microbiological analyses carried out on the different samples of grilled meat, the results obtained were compared to the Canadian standard ISO / IEC $17025, \mathrm{~N}^{\circ} 131$ of 2009 . These results were treated according to the germs indicating Good Manufacturing Practice (GMP) and Hygiene (BPH).

Table 1. Enumeration of E. coli and Staphylococci in grilled meat samples and the hygienic quality of these samples

\begin{tabular}{|c|c|c|c|c|}
\hline Sampling area & No. of samples & $\begin{array}{c}\text { E. coli } \\
\text { (CFU / g sample) }\end{array}$ & Staphylococci (CFU / g sample) & Hygienic quality of samples \\
\hline \multirow{10}{*}{ Zongo } & 1 & 2.1 .102 & $>3.108$ & QHNS \\
\hline & 2 & - & 1.104 & QHNS \\
\hline & 3 & 4.101 & $>3.107$ & QHNS \\
\hline & 4 & - & 3.6 .104 & QHNS \\
\hline & 5 & 1.103 & $>3.108$ & QHNS \\
\hline & 6 & 5.7 .102 & $>3.105$ & QHNS \\
\hline & 7 & 6.101 & $>3.105$ & QHNS \\
\hline & 8 & - & 1.5 .105 & QHNS \\
\hline & 9 & - & 1.6 .104 & QHNS \\
\hline & 10 & 4.101 & $>3.105$ & QHNS \\
\hline \multirow{10}{*}{ Gbégamey } & 1 & - & $>3.108$ & QHNS \\
\hline & 2 & - & 4.3 .103 & QHA \\
\hline & 3 & - & 5.103 & QHA \\
\hline & 4 & - & 2.1 .103 & QHA \\
\hline & 5 & - & $<4.102$ & QHS \\
\hline & 6 & 4.103 & 9.1 .103 & QHNS \\
\hline & 7 & $2,3,102$ & 3.8 .103 & QHNS \\
\hline & 8 & 3.105 & 5.101 & QHNS \\
\hline & 9 & - & 1.8 .105 & QHNS \\
\hline & 10 & - & 6.8 .104 & QHNS \\
\hline \multirow{10}{*}{ Mènontin } & 1 & - & 3.1 .105 & QHNS \\
\hline & 2 & - & 1.7 .105 & QHNS \\
\hline & 3 & - & 4.7 .103 & QHA \\
\hline & 4 & - & 2.5 .105 & QHNS \\
\hline & 5 & - & 1.8 .103 & QHA \\
\hline & 6 & - & 4.103 & QHA \\
\hline & 7 & - & $<4.102$ & QHA \\
\hline & 8 & - & 4.1 .103 & QHA \\
\hline & 9 & - & $>3.105$ & QHNS \\
\hline & 10 & - & $>3.105$ & QHNS \\
\hline Standards & - & $\mathrm{m}: 10 ; \mathrm{M}: 102$ & $\mathrm{~m}: 102 ; \mathrm{M}: 104$ & - \\
\hline
\end{tabular}


42

It was noted that 9 meat samples were carriers of $E$. coli with a contamination rate of $30 \%$. Among these contaminated samples, $20 \%$ were of unsatisfactory hygienic quality as contained a quantity of E. coli higher than tolerated by the standard. All the analysed samples were infested with staphylococci, which lead to a contamination rate of $100 \%$, of which $60 \%$ contained a quantity of staphylococcus exceeding the threshold tolerated by the standard. $70 \%(21 / 30)$ of these meat samples were of unsatisfactory hygienic quality (100\% from Zongo; $60 \%$ Gbégamey and 50\% Mènontin), $26.67 \%(08 / 30)$ were of acceptable hygienic quality and $3.33 \%(01 / 30)$ of satisfactory hygienic quality (Table 1 ).

\section{Identification of Staphylococcus aureus}

Of the $100 \%$ sample contamination rate by Staphylococci, it was noted that the catalase search was positive on the 30 Staphylococci strains. 80\% (24/30) of these strains produce free staphylocoagulase with a predominance of strains from Gbegamey $(06 / 10)$. Of the 24 coagulase-positive strains, 11 were Dnase positive, hence Staphylococcus aureus. However, of the 30 samples of roast meats analysed, 11 were contaminated with $S$. aureus, with a high prevalence of samples from Zongo (60\%) (Table 2).

Resistance profile of bacterial strains isolated from antibiotics

$S$. aureus ATCC 25923 and E. coli ATCC 25922 showed sensitivity to all antibiotics used. All strains of $S$. aureus and E. coli were resistant to at least one antibiotic (Table 3 and 4).

Considering that a multidrug-resistant strain is resistant to at least 3 antibiotics of different families, $72.72 \%(08 / 11)$ of $S$. aureus strains are declared as such, with strong resistance of strains to cefotaxime and combination amoxicillin + clavulanic acid (Table 3). As for the strains of E. coli, 88.89\% (08/09) are MDR, with a strong resistance to ciprofloxacin, cefotaxime and nalidixic acid. It should be noted that no strain of E. coli was resistant to gentamicin (Table 4).

Table 2. Results of biochemical identification tests for Staphylococci

\begin{tabular}{|c|c|c|c|c|c|c|c|}
\hline \multicolumn{8}{|c|}{ Results of biochemical identification tests } \\
\hline Sampling area & \multicolumn{2}{|c|}{ Catalase } & \multicolumn{2}{|c|}{ Coagulase } & \multicolumn{2}{|c|}{ DNase } & Total \\
\hline & - & + & - & + & - & + & \\
\hline Zongo & 00 & 10 & 02 & 08 & 04 & 06 & 10 \\
\hline Gbégamey & 00 & 10 & 01 & 09 & 07 & 03 & 10 \\
\hline Mènontin & 00 & 10 & 03 & 07 & 08 & 02 & 10 \\
\hline \multirow{2}{*}{ Total } & 00 & 30 & 06 & 24 & 19 & 11 & \multirow{2}{*}{30} \\
\hline & $(0 \%)$ & $(100 \%)$ & $(20 \%)$ & $(80 \%)$ & $(63.33 \%)$ & $(36.67 \%)$ & \\
\hline
\end{tabular}

- : negative test $;+:$ positive test

Table 3. Resistance profile of Staphylococcus aureus strains

\begin{tabular}{clc}
\hline Bacterial strains & Phenotypes & Number of isolates \\
\hline S. aureus ATCC 25923 & CTX S, AMC S, CN S, IPM S & 01 \\
& CTX R, AMC R, CN R, IPM R & 03 \\
S. aureus isolated & CTX R, AMC S, CN R, IPM R & 04 \\
& CTX R, AMC R, CN I, IPM R & 01 \\
& CTX S, AMC R, CN S, IPM S & 02 \\
\hline
\end{tabular}

S. aureus: Staphylococcus aureus; CTX: Cefotaxime; AMC: Amoxicillin + clavulanic acid; CN: Gentamycin; IPM: Imipenem; R: Resistant; S: Sensible; I: Intermediate

Table 4. Stem resistance profile of Escherichia coli

\begin{tabular}{clr}
\hline Bacterial strains & \multicolumn{1}{c}{ Phenotypes } & Number of isolates \\
\hline E. coli ATCC 25922 & $\mathrm{CIP}^{\mathrm{S}}, \mathrm{CN}^{\mathrm{S}}, \mathrm{CTX}^{\mathrm{S}}, \mathrm{NA}^{\mathrm{S}}$ & 01 \\
& $\mathrm{CIP}^{\mathrm{R}}, \mathrm{CN}^{\mathrm{S}}, \mathrm{CTX}^{\mathrm{R}}, \mathrm{NA}^{\mathrm{R}}$ & 01 \\
E. coli isolated & $\mathrm{CIP}^{\mathrm{R}}, \mathrm{CN}^{\mathrm{I}}, \mathrm{CTX}^{\mathrm{R}}, \mathrm{NA}^{\mathrm{R}}$ & 05 \\
& $\mathrm{CIP}^{\mathrm{R}}, \mathrm{CN}^{\mathrm{S}}, \mathrm{CTX}^{\mathrm{R}}, \mathrm{NA}^{\mathrm{R}}$ & 02 \\
$\mathrm{CIP}^{\mathrm{I}}, \mathrm{CN}^{\mathrm{S}}, \mathrm{CTX}^{\mathrm{R}}, \mathrm{NA}^{\mathrm{R}}$ & 01 \\
\hline
\end{tabular}

E. coli: Escherichia coli; CIP: Ciprofloxacin; CN: Gentamycin; CTX: Cefotaxime; NA: Nalidixic acid; R: Resistant; S: Sensible; I: Intermediate 


\section{Discussion}

The present study showed that the samples analysed were contaminated with grilled meats Staphylococci and $E$. coli with microbial loads for the most part superior to those allowed by the standard. Of the 30 samples analysed, 6 (six) had microbial load in $E$. coli superior to the requirements of the standard; a percentage of $20 \%$ of samples that do not comply with the standard. At the same time, $100 \%$ of the samples contain Staphylococci, 60\% of which contain a quantity of Staphylococcus exceeding the threshold tolerated by the standard. These results show that the principle HACCP is not respected all along the chain of production of these grilled meats. A similar observation was made by Boko et al. in 2017 who found in the samples of Tchatchanga taken at Bohicon and Hillacondji service stations (3.81.103 to 4.28.103 CFU / g sample) of $E$. coli and a high rate of staphylococci. These results are also in the same direction as those obtained by Bennani et al. in 2016 which explain that the presence of $E$. coli is due to unsatisfactory hygiene conditions in the treatment of meat and explain the presence of staphylococci by the contamination of samples by a carrier individual at any stage of treatment (scratching) skin, sneezing, dirty hair unprotected or by the animal because the seed present superficially can migrate inwards during the cutting and finally because of bad cooking meat. $70 \%$ (21/30) of these meat samples were of unsanitary hygienic quality $(100 \%$ from Zongo; $60 \%$ of Gbegamey and $50 \%$ of Mènontin). This is explained by the fact that Zongo holds a better place on the list of the most polluted areas of Cotonou (Benin South) or the majority of the population does not observe the basic rules of hygiene.

These generally uncovered products are exposed to air pollution. The presence of these germs testifies to the insalubrity of the sellers (Ilboudo et al., 2010). Sellers, who do not wash their hands but regularly wipe themselves with unsuitable tea towel, use the pieces with their hands and utensils that are never washed. Moreover, of the 30 strains of Staphylococci, $80 \%$ are producers of free staphylocoagulase, a source of severe food poisoning. Not to mention the $36.67 \%(11 / 30)$ which are Staphylococcus aureus.

With regard to the resistance profile of the strains, the two reference strains used are sensitive to all the antibiotics used. This result allowed us to check the quality of our antibiotics and validate our results. Tables 3 and 4 show that grilled meats consumed by the population of southern Benin are contaminated with $S$. aureus and $E$. coli multidrug. The majority of isolated strains are resistant to at least one antibiotic.

The strains of $E$. coli were only sensitive to gentamicin $30 \mu \mathrm{g}$. These results are similar to those obtained by Van and his colleagues in 2008, while, $63.64 \%$ of strains of $S$. aureus were sensitive to gentamycin and $72.7 \%$ to imipenem. These results are consistent with those obtained by Chaalal (2013), which shows a multidrug resistance of $83.9 \%$ of $S$. aureus strains.

\section{Conclusions}

The hereby study brings new knowledge on the level of contamination, the hygienic quality of grilled meats sold on the streets of Cotonou and the resistance profile of strains of $E$. coli and circulating $S$. aureus. Indeed, the presence of a bacterium in a food is not enough to say that it is responsible for food poisoning; it has to be further argumented by analysis and toxicogenic equipment. Thus bacterial counting methods must be coupled with the search for virulence factors. The knowledge of the toxicogenic profile allows pushing further the methods of diagnosis and consequently better management of patients. This study also showed that extra-hospital strains of $S$. aureus and $E$. coli can be multi-resistant. It would be important to study the link between the carrying of bacteria by sellers and their presence in grilled meats in order to conclude with precision on the origin of the contaminations. Street foods are therefore a major public health problem, given their economic and social importance in developing countries like Benin. It is thus necessary to put in place several strategies aimed at ensuring health security by epidemiological surveillance of diseases transmitted by street foods. Sellers must be educated particularly in the field of food hygiene.

\section{References}

Ahouandjinou H, Baba-Moussa F, Gbaguidi B, Sina H, Adeoti K, Mousse W (2016). Antibiotic resistance and virulence factors of isolated Escherichia coli strains of bovine carcasses from Benin. European Scientific Journal 12(33):1857-7881.

Bankolé HS, Baba-Moussa F, Agbankpé JA, Dougnon TV, Lègonou M, ... Baba-Moussa L (2012). Campylobacter isolation test in poultry meat in the Republic of Benin. International Journal of Biological and Chemical Sciences 6(5):1979-1986.

Benaissa A, Ould El Hadj Khelil A, Adamou A, Babelhadj B, ... Riad A (2014). Quality of camel meat in slaughter houses of Ouargla in Algeria. II. Superficial bacterial contamination of carcasses. Journal of Livestock andVeterinary Medicine in Tropical Countries 67(4):229-233.

Benniani Leila, Sanae Berrada, Bouchra Salame, Mohamed Aabouch, El Ouali Lalami Abdelhakim (2016). Evaluation of the hygienic quality of meat and certain meat products taken from the city of Fes, Morocco. International Journal of Innovation and Applied Studies 15(3):547554 .

Boko K, Gangnito M, Toleba S, Sessou P, Tougan U, Aguidissou O, Kpodekon M, Farougou S (2017). Microbial quality of "Tchachanga”, a barbecued mutton sold in Benin. Advances in Microbiology 7:633-640.

Chaalal Wafaa (2013). Occurrence and antimicrobial resistance profile of Staphylococcus aureus isolated from food products. University of Es Senia Oran. Memory for obtainingmagister, pp 115.

Cohen N, Ennaji H, Hassar M, Karib H (2006). The bacterial quality of meat and offal in Casablanca (Morocco). Molecular Nutrition \& Food Research 50(6):557-562. 
44

Delmas G, Gallay A, EspiéE, HaeghebaertS, Pihier N, ... Desenclos J(2006). Collective food poisoning in France between 1996 and 2005. Bulletin Epidemiologique Hebdomadaire 51-52:418-422.

Djenidi R (2016). Study of the superficial contamination of sheep carcasses using bacteriological examinations at the abattoir of Bordj Bou Arréridj. Biannual review - Ferhat Abbas University Setif 1, Agriculture Review 12:47-56.

El-HadefElOkkiS, El-Groud R, KenanaH,QuessyS (2005). Evaluation of the superficial contamination of bovine and ovine carcasses from the municipal abattoir of Constantine in Algeria. Canadian Veterinary Journal 46(6):638-640.

J Pit, Cappelier JM, Laroche M, Fradin N, Giraudet K, Magras C (2006). Beef meat: An analysis of biological hazards for the consumer applied to the slaughterhouse. Meeting Research Ruminants 13:411-414.

Ilboudo André, Savadogo Aly, Nicolas Barro, Seydi Malang, Traoré Alfred (2010). Microbiological quality of meat used in catering: case of the academics of Ouagadougou, Burkina-Faso. Revue de Microbiologie Industrielle, Sanitaire et Environnementale 4(1):99-113.

KhallafM, Benbakhta B, Nasri I, Sarhane B, Senouci S, Ennaji MM(2014). Prevalence of Staphylococcus aureus isolated from market meat in Rabat, Morocco. International Journal of Innovation and Applied Studies 7(4):1665-1670.
Martins IM, Kabuki DY, Miya NTN, Pereira JL (2014). Occurrence and characterization of enterotoxigenic potential of staphylococcal isolates from dairy products. Journal of Food Safety 34(3):185-192.

Salifou CFA, Boko KC, Attakpa YE, Agossa R, Ogbankotan I, Farougou S (2013). Evaluation of the bacteriological quality of fresh meat of cattle slaughtered at slaughterhouses Cotonou-Porto-Novo during the distribution chain. Journal of Animal \& PlantScience 17(2):2567-2579.

Van TTH, Chin J, Chapman T, Tran LT, Coloe PJ (2008). Safety of meat and shellfish in Vietnam: An analysis of Escherichia coli isolations for antibiotic resistance and virulence genes. International Journal of Food Microbiology 124(3):217-223.

WHO (World Health Organization). WHO Estimates of the global burden of foodborne diseases; Foodborne disease burden epidemiology reference group 2007-2015. Available on the link: http://apps.who.int/iris/bitstream/10665/199350/1/978924156516 5 _eng.pdf?ual.

Yeni F, Acar S, Polat ÖG, Soyer Y, Alpas H (2014). Rapid and standardized methods for detecting foodborne pathogens and mycotoxins on fresh produce. Food Control 40:359-367. 